\title{
УДК 334:631.1
}

\section{Х. А. Абдурахмонов}

Санкт-Петербургский государственный университет, Санкт-Петербург, Пушкин, e-mail: huseynjon-1@mail.ru

\section{СУЩНОСТЬ, ЦЕЛИ И ВОЗМОЖНОСТИ БИЗНЕС-АНАЛИЗА}

Ключевые слова: бизнес-анализ, финансовая устойчивость.

Организация может быть признана финансово устойчивой в том случае, если она имеет защиту от внешних негативных факторов, не имеет высокой степени зависимости от кредиторов и находится вне зоны риска банкротства. Принимая во внимание взаимосвязь и сложную структуру взаимодействия множества составляющих финансовой системы и реальной экономики, измерение финансовой устойчивости достаточно непростая процедура. Есть множество исследований, которые нацелены на попытку найти условия финансовой стабильности при помощи определенных показателей уязвимости финансовой системы. Но действительную ситуацию в отношении финансовой устойчивости, используя некоторое количество показателей, оценить достаточно сложно, особенно в долгосрочной перспективе. В современных условиях необходимы более расширенные методы анализа финансовой составляющей, чем просто комплексный анализ деятельности организации. Именно бизнес-анализ является тем инструментом, который в состоянии охватить самый большой спектр вопросов в отношении выявления потребностей бизнеса и преодоления возникающих сложностей. Для понимания реальной области, которую охватывает современный бизнес-анализ, стоит рассмотреть его определение и сущность.

\section{H. A. Abdurakhmonov}

St. Petersburg State University, St. Petersburg, Pushkin, e-mail: huseynjon-1@mail.ru

\section{THE ESSENCE, GOALS, AND CAPABILITIES OF BUSINESS ANALYSIS}

Keywords: business analysis, financial stability.

An organization can be recognized as financially stable if it has protection from external negative factors, does not have a high degree of dependence on creditors and is not at risk of bankruptcy. Taking into account the relationship and complex structure of interaction between the many components of the financial system and the real economy, measuring financial stability is a rather complicated procedure. There are many studies that try to find the conditions of financial stability using certain indicators of the vulnerability of the financial system. But the actual situation with regard to financial stability, using a certain number of indicators, is quite difficult to assess, especially in the long term. In modern conditions, more advanced methods of analyzing the financial component are needed than just a comprehensive analysis of the organization's activities. It is business analysis that is the tool that is able to cover the largest range of issues in terms of identifying business needs and overcoming emerging difficulties. To understand the real area covered by modern business analysis, it is worth considering its definition and essence.

\section{Введение}

При проведении бизнес-анализа финансовой устойчивости предприятия могут быть использованы различные методы или модели анализа. При этом важно осознавать, что бизнес-анализ - это нечто большее, чем анализ хозяйственной деятельности организации. Учитывая новизну денного направления анализа, сегодня не все руководители сельскохозяйственных организаций осознают это различие. Более того, большинство не видят острой необходимости вообще в применении бизнес-анализа для развития и укрепления своего бизнеса.

Цель исследования состоит в этимологическом исследовании определения «бизнес-анализ», а также в изучении основополагающих концепций бизнес-анализа.

\section{Материал и методы исследования}

Методологическую основу исследования составила система теоретических и общенаучных методов познания, таких как анализ и системный подходы. 


\section{Результаты исследования и их обсуждение}

Для понимания реальной области, которую охватывает современный бизнесанализ, стоит рассмотреть его определение и сущность. Синергия определений «бизнес» и «анализ» определила появление нового вида исследовательской деятельности на микроуровне. Новые глобальные тенденции в экономике явились причиной возникновению и развитию бизнес-анализа.

На сегодняшний день Международным институтом бизнес-анализа (IIBA) разработан набор знаний в области бизнес-анализа Business Analysis Body of Knowledge 3.0 (ВАВОК). В данном своде дается определение бизнес-анализу, определяющее его, как набор задач и методов, которые применяются как связующее звено между заинтересованными сторонами для понимания общей структуры организации, его политики и операций, для принятия последующих управленческих решений [1].

В данном руководстве представлена следующая модель понятий бизнес-анализа (рис. 1).

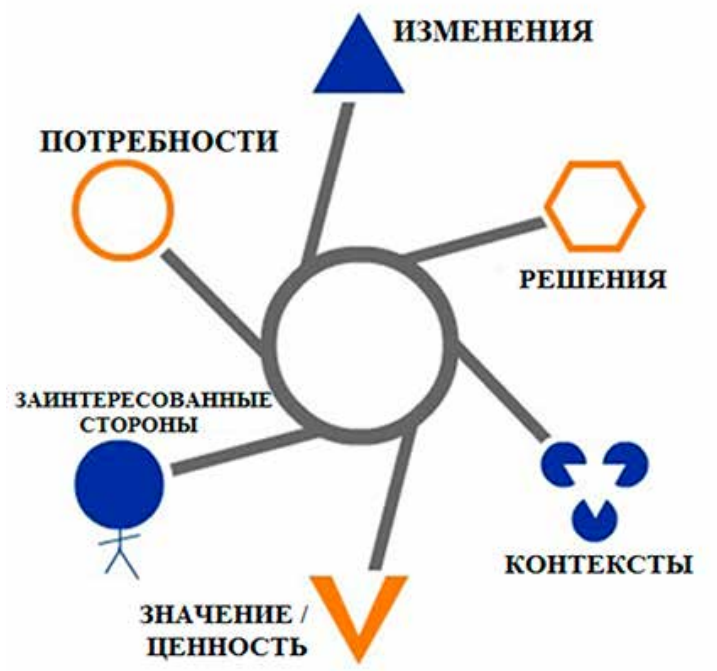

Рис. 1. Модель концеепций (понятий) бизнес-анализа [2]

Каждая ключевая концепция - это идея, которая содержит основополагающее значение для практики бизнес-анализа. Все концепции равны и необходимы, а каждая из них определяется другими пятью ключевыми концепциями. Между всеми ними существуют причинно-следственные связи. Взаимосвязь этих концепций образует но- вую концептуальную модель Бизнес-анализа (рис. 2).

При изменении любой из представленных на рис. 2 концепций происходит пересмотр остальных концепций и их взаимосвязей, что крайне важно. При этом ошибочным решением будет рассматривать их изолированно.

По нашему мнению, понятие «бизнесанализ» более емкое, чем определение «бизнес-аналитика». Многие зарубежные экономисты придерживаются подобного мнения и относят бизнес-анализ к исследовательским дисциплинам. [4]

По мнению Бариленко В. И., бизнес-анализ необходимо рассматривать, как «этап логического развития комплексного экономического анализа, связанный с изучением бизнес-процессов, бизнес-единиц и бизнес-моделей коммерческих организаций». Бизнес-анализ определяется как средство, способствующее реализации принципов социальной ответственности бизнеса и обеспечивающее определенные условия для эффективного развития отдельных организаций и общества в целом [5].

Горшкова Л.А. считает, что бизнес-анализ - это важный компонент для реализации основных функций управления, планирования или иных функций. Инструмент для ретроспективного и перспективного анализов [6].

Отличие бизнес-анализа от комплексного экономического анализа хозяйственной деятельности в том, что в первом случае анализируется не только внутренняя деятельность организации, т.е. бизнес, но и проводится исследование внешней среды. В таком случае содержание бизнес-анализа схематично можно изобразить следующим образом (рис. 3).

Каждый из представленных видов анализа на рис. 3 является в достаточной мере изученным. Анализ макроокружения включает в себя анализ налоговой политики, трудового законодательства и других важнейших правовых актов; изучение геополитической системы региона, в котором ведется предпринимательская деятельность; анализ последних достижений в технологии производства и продвижения продукции и др. В процессе анализа бизнеса анализируются бизнес-процессы (технологии их реализации); анализ продукции; анализ состояния (износа) оборудования; анализ и оценка персонала и др. 


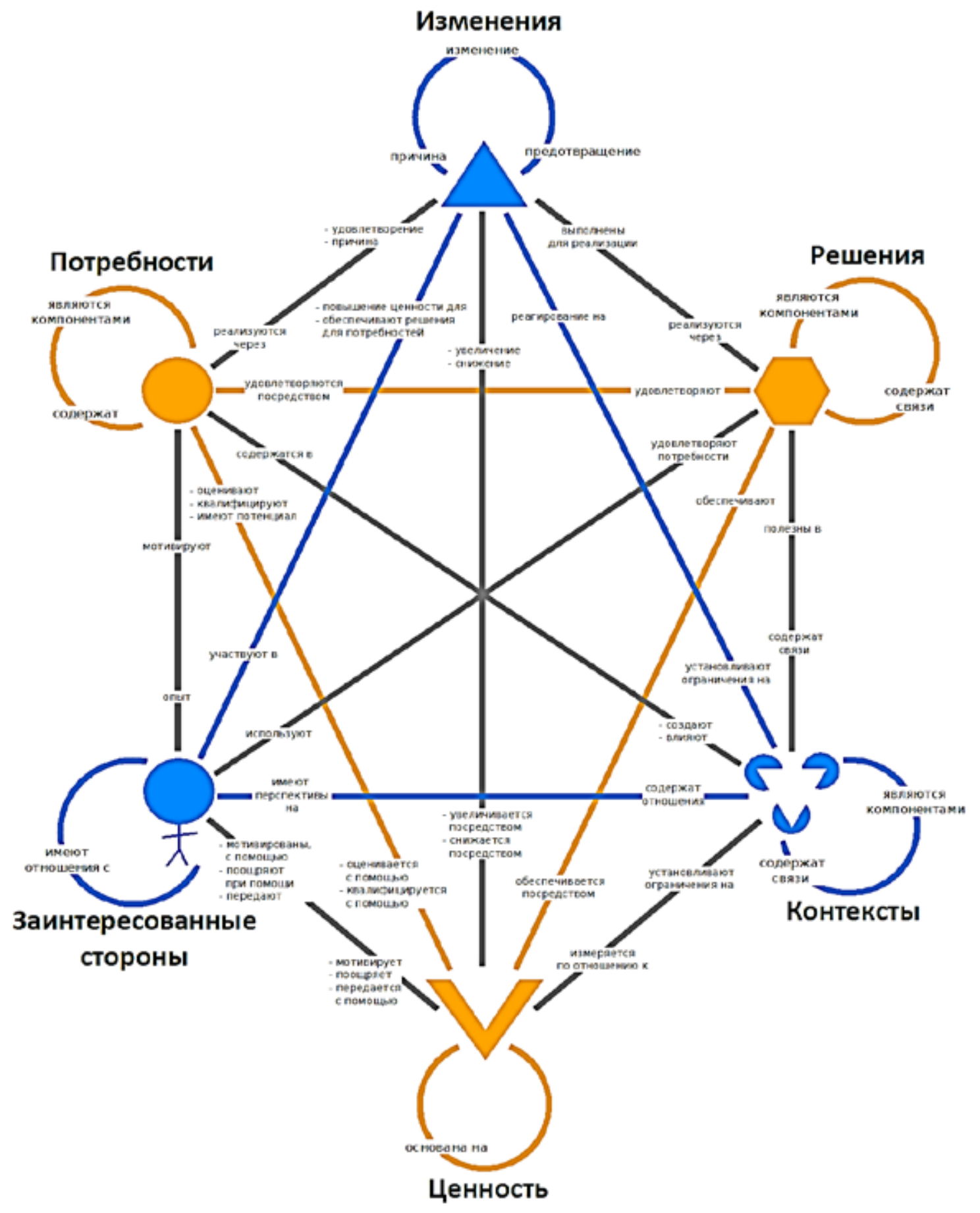

Рис. 2. Новая кониептуальная модель связей понятий бизнес-анализа [3]

Следует подчеркнуть, что довольно сложно отделить анализ окружающей среды от анализа бизнеса. Например, анализ требований клиентов предполагает не только изучение потребностей клиентов, но и оценку бизнеса с точки зрения клиентов; анализ конкурентной позиции наряду с оценкой конкурентов включает оценку уровня компании по отношению к конкурентам [7]. В связи с этим понятие «бизнес-анализ», на наш взгляд, не следует отождествлять ни с одной из перечисленных областей анализа, поскольку данная аналитическая область с одной стороны содержит элементы методологии каждой из перечисленных областей (видов анализа), а с другой-содержит только присущие ей признаки. 


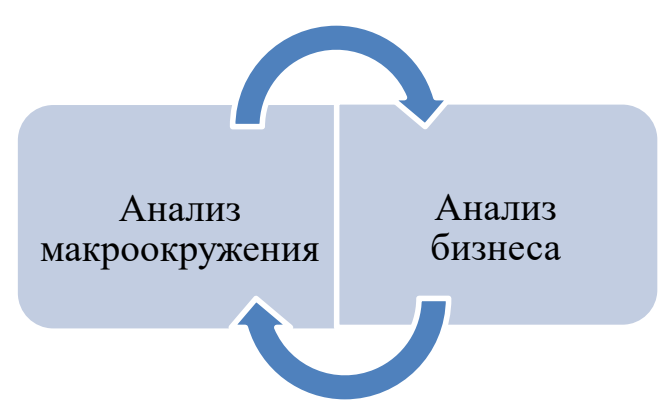

Рис. 3. Структура бизнес-анализа (составлено автором)

Таким образом, содержание бизнес-анализа является комплексным сочетанием этих видов анализов. Тогда содержание бизнесанализа, на наш взгляд, следует изобразить несколько иначе (рис. 4).

В данном случае мы наглядно убеждаемся, что изменение любого из элементов может привести к изменению другого. Соответственно при попытке принять управленческое решение необходимо рассмотреть взаимосвязь всех элементов и их возможные изменения.

Наиболее полным определением функций бизнес-анализа, на наш взгляд явля- ется следующее мнение о содержании бизнес-анализа:

- анализ предприятия - бизнес-анализ сосредоточивается на изучении и понимании общих потребностей организации.

- планирование и управление требованиями - определяются основные требования, выполняется управление изменениями.

- сбор требований - описывается методика сбора требований от заинтересованных сторон.

- анализ требований - описываются, разрабатываются и детализируются требования необходимые для дальнейшей успешной реализации.

- коммуникация требований - описываются методики, гарантирующие то, что у всех заинтересованных сторон присутствует общее понимание конкретных требований и последующих способов их реализации.

- проверка и оценка правильности решения - разрабатывается алгоритм, с помощью которого бизнес-аналитик в последствии осуществит проверку правильности предложенного решения.

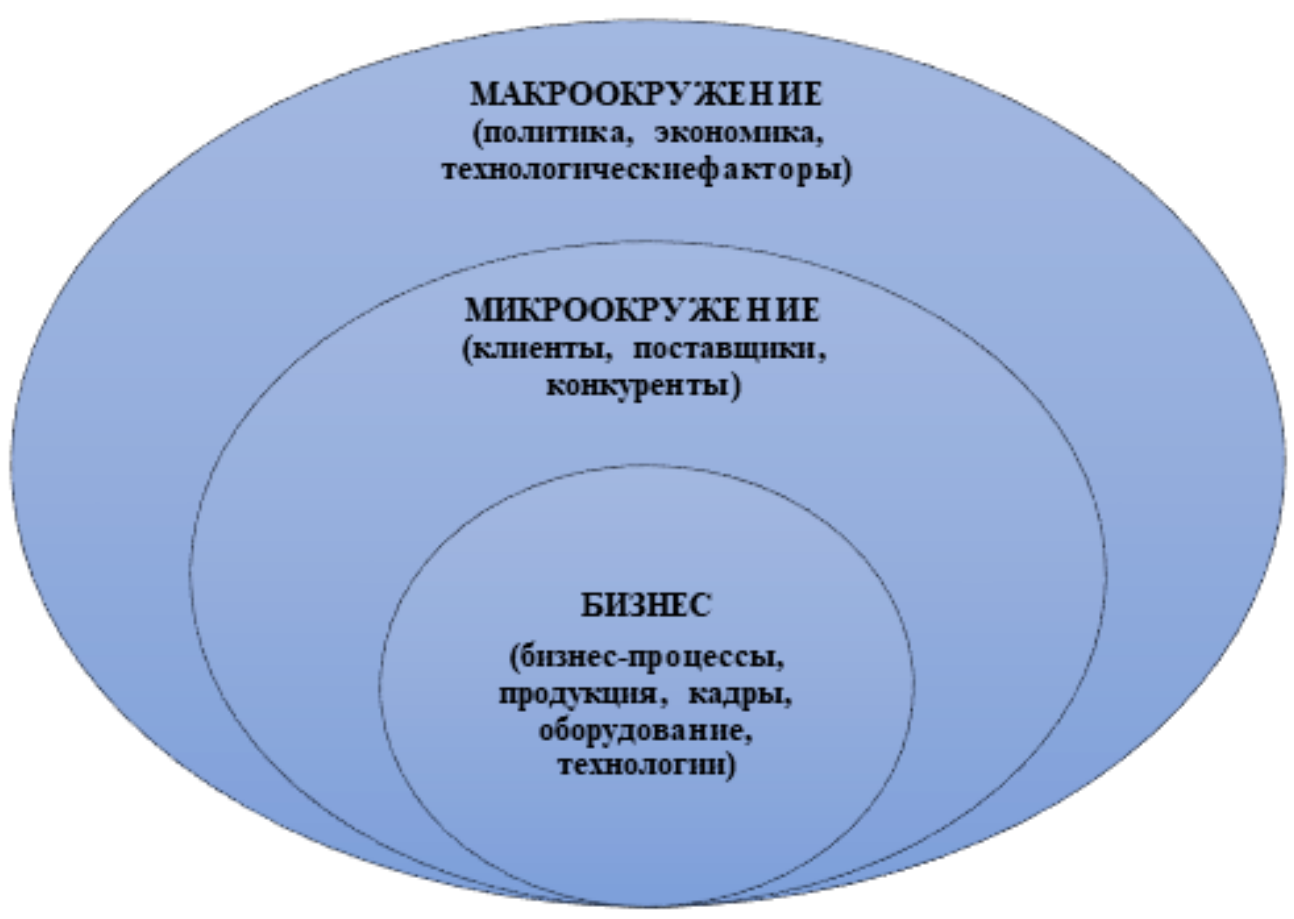

Рис. 4. Комплексное содержание бизнес-анализа (составлено автором) 
Библиографический список

1. BABOK GUIDE - свод знаний по бизнес-аналитике. [Электронный ресурс]. 2021. Дата обновления: 05.02.2021. URL: https://hsbi.hse.ru/articles/babok-guide-business-analysis-body-of-knowledge/ (дата обращения: 05.02.2021).

2. Мастерская бизнес-анализа. [Электронный ресурс]. 2021. Дата обновления: 05.02.2021. URL: https:// blog.business-analyst.info/2014/05/17/chto-mi-znaem-o-babok-guide-version-3/ (дата обращения: 05.02.2021).

3. База знаний по бизнес-анализу. [Электронный ресурс]. 2021. Дата обновления: 05.02.2021. URL: https://analytics.infozone.pro/review-article-on-babok-v3-in-russian-download/ (дата обращения: 05.02.2021).

4. Kathleen B Hass, Richard Vander Horst, Kimi Ziemski (2008). From Analyst to Leader: Elevating the Role of the Business Analyst Management Concepts, 2008. 94 p.

5. Бариленко В.И. и др. Основы бизнес-анализа: учебное пособие / под ред. В.И. Бариленко. М.: КНОРУC, 2014. $272 \mathrm{c}$.

6. Горшкова Л.А. Теория бизнес-анализа: учебное пособие: 2-е изд. Нижний Новгород: Изд-во Нижегородского госуниверситета, 2011. $354 \mathrm{c}$.

7. Силич В.А., Силич М.П. Моделирование и анализ бизнес-процессов: учеб. пособие. Томск: Изд-во Томск. гос. ун-та систем управления и радиоэлектроники, 2011. 212 с. 